\title{
Dimensões dos Riscos nas Políticas de Combate à Violência Contra a Mulher Durante a Pandemia de COVID-19 em Aracaju (Sergipe). Risk Dimensions in Policies to Combat Violence Against Women During COVID-19 in Aracaju (Sergipe).
}

\author{
Thaís Santos Doria ${ }^{1}$ \\ Gustavo Torres de Brito Daier ${ }^{2}$ \\ Kleverton Melo De Carvalho ${ }^{3}$ \\ Rosângela Sarmento Silva ${ }^{4}$
}

\section{Resumo}

Relatórios de organizações internacionais e notícias veiculadas na mídia têm apontado o aumento do número de casos de violência doméstica e familiar contra a mulher -VDFM, durante a pandemia da Covid-19. Diante disso, é fundamental compreender a efetividade das políticas públicas desenvolvidas. O objetivo deste trabalho é analisar as dimensões dos riscos nas políticas de combate à VDFM no período de crise sanitária. A pesquisa utilizou um desenho qualitativo de estudo de caso único, sendo a unidade de caso o Departamento de Atendimento a Grupos Vulneráveis - DAGV e, como sujeito da pesquisa, a Delegacia de Atendimento à Mulher - DEAM. A técnica de análise de conteúdo foi utilizada em quatro entrevistas concedidas por servidores do quadro do DAGV. Também foi realizada análise documental em 210 inquéritos abertos entre maio e julho de 2020. Verificou-se que o rol de medidas protetivas de urgência trazidas pela Lei Maria da Penha - LMP - e demais instrumentos de gestão de risco contribuem com a efetividade dos trabalhos da rede de apoio e enfrentamento à VDFM. Porém, há fragilidades que devem ser corrigidas, tais como estrutura física do DAGV, ampliação do efetivo policial, atualização e ampliação do Formulário Nacional de Avaliação de Riscos, atuação multidisciplinar articulada e atualização de práticas de gestão gerencial em toda a rede de apoio. $O$ trabalho contribuiu com a identificação de fatores de riscos no atendimento inicial às vítimas e também na fase de andamento do inquérito. Por fim, faz a apresentação de sugestões para mitigá-los e/ou evitá-los.

Palavras-chave: Violência Doméstica. Gestão de Riscos. Pandemia. Aracaju/SE.

\begin{abstract}
Reports from international organizations and news broadcasted in the media have pointed out the increase in the number of cases of domestic and family violence against women -VDFM, during the Covid-19 pandemic. Given this, it is essential to understand the effectiveness of the public policies developed. The objective of this paper is to analyze the dimensions of risks in policies to combat VDFM in the period of health crisis. The research used a qualitative design of single case study, being the case unit the Department of Attendance to Vulnerable Groups - DAGV and, as subject of the research, the Police Station of Attendance to Women - DEAM. The technique of content analysis was used in four interviews given by employees of the DAGV. Documentary analysis was also carried out in 210 inquiries opened between May and July 2020. It was verified that the list of urgent protective measures brought by the Maria da Penha Law - LMP - and other instruments of risk management contribute to the effectiveness of the work of the network of support and confrontation to the VDFM. However, there are weaknesses that must be corrected, such as the physical structure of the DAGV, expansion of the police force, updating and expansion of the National Risk Assessment Form, articulated multidisciplinary action, and updating of management practices throughout the support network. The work contributed with the identification of risk factors in the initial care to the victims and also in the progress phase of the investigation. Finally, it makes suggestions to mitigate and/or avoid them.
\end{abstract}

Keywords: Domestic Violence. Risk Management. Pandemic. Aracaju/SE.

Manuscript first received/Recebido em: 21/08/2021

Manuscript accepted/Aprovado em: 07/11/2021

${ }^{1}$ Mestranda em Administração Pública (PROFIAP) pela Universidade Federal de Sergipe. Assistente em Administração na Universidade Federal de Sergipe. São Cristóvão, Sergipe, Brasil. E-mail: thaisdoria@academico.ufs.br.

${ }^{2}$ Mestrando em Administração Pública (PROFIAP) pela Universidade Federal de Sergipe. Assistente em Administração na Universidade Federal de Sergipe. São Cristóvão, Sergipe, Brasil. E-mail: gdaier@academico.ufs.br.

${ }^{3}$ Doutor em Administração. Professor do Programa de Pós-Graduação Profissional em Administração Pública da Universidade Federal de Sergipe (UFS). São Cristóvão Sergipe, Brasil. E-mail: kleverton1@academico.ufs.br.

${ }^{4}$ Doutora em Administração. Professora do Programa de Pós-Graduação em Administração e do Programa de Pós-Graduação Profissional em Administração Pública da Universidade Federal de Sergipe (UFS). São Cristóvão Sergipe, Brasil. E-mail: rosangelasarmento13@gmail.com. 


\section{INTRODUÇÃO}

Esta pesquisa analisa as dimensões dos riscos nas políticas de combate à Violência Doméstica e Familiar contra a Mulher - VDFM, no período da pandemia pelo SARS-COV-2. A VDFM é um problema de âmbito mundial e, atualmente, é considerada uma questão de saúde pública. As Nações Unidas entendem que a violência contra a mulher se constitui como qualquer ato de violência baseado no gênero que tenha como resultado - ou possa resultar - danos psicológicos, sexuais ou físicos, ou sofrimento da mulher, inserindo-se ameaças de tais atos, coerção ou privação arbitrária da liberdade, caso ocorra na vida pública ou privada (ONU, 1993). Sabendo disso, é pertinente pontuar que no Brasil a taxa de feminicídio é a quinta maior no mundo em um grupo composto por 83 países com dados homogêneos, segundo estatísticas da Organização Mundial da Saúde (ONU, 2016). Em uma perspectiva nacional, no primeiro ano pandêmico, o número absoluto de feminicídios chegou a 1.350 vítimas - 1,2 mortes por grupo de 100 mil pessoas (FBSP, 2021).

Essa realidade, dentro do contexto de isolamento social como medida preventiva de disseminação do novo coronavírus, tem gerado uma elevação do número de casos de feminicídio e de VDFM. Relatórios de organizações internacionais e notícias veiculadas na mídia têm apontado a elevação do número de casos dessa violência (Peterman et al., 2020). Durante o período de $1^{\circ}$ a 25 de março de 2020 , houve um aumento de $17,97 \%$ no número de denúncias registradas através dos serviços Disque 100 e Ligue 180 (BRASIL. Ouvidoria Nacional dos Direitos Humanos (ODNH), do Ministério da Mulher, 2020). A Justiça do Rio de Janeiro, estimou um aumento de $50 \%$ nos plantões de atendimento a vítimas de VDFM no início do isolamento social (Bassan, 2020). Também se observou um aumento dos casos de feminicídio no primeiro trimestre no ano de 2020 em alguns estados - Ceará, Tocantins, Rio grande do Sul; com aumentos de 60\%, 300\%, 73\%, respectivamente. (CEARÁ, 2020; RIO GRANDE DO SUL, 2020; TOCANTINS, 2020).

Além disso, segundo o Fórum Brasileiro de Segurança Pública, 76,4\% das mulheres vítimas de VDFM afirmaram que o agressor era alguém com quem convivia: um cônjuge, namorado, vizinho, ex-namorado ou companheiro; 42\% dessas mulheres declararam-se vítimas de algum tipo de violência dentro do seu ambiente doméstico, revelando exposição a esse risco dentro de suas próprias casas (Bueno \& Lima, 2019). Sabendo disso, é importante considerar que, durante o isolamento social, as mulheres estão convivendo ainda mais tempo com os autores de violência, principalmente aquelas que estavam em processo de denúncia dessas violências (Peres, 2020). Pode-se supor então que a principal causa do aumento da VDFM decorre do maior tempo de convivência da vítima com o agressor - o aumento do estresse causado pelo isolamento social pode ser um gatilho para mais atitudes violentas.

Em Sergipe, a realidade da VDFM vem sendo mitigada. Os casos no Estado caíram de 167 para 119 no período de março a julho de 2020 em comparação ao mesmo período do ano anterior, ou seja, houve uma queda de $28,7 \%$ (Jorge et al., 2020). Daí, emerge a 
seguinte questão: Como se deu essa redução local, com um cenário geral internacional e brasileiro de agravamento dessa violência? Diversos trabalhos internacionais, como os de Abuhammad (2020); Espinosa-Bejarano (2020); Bradbury-Jones \& Isham (2020); GrahamHarrison et al. (2020); Nittari et al. (2021); Noman et al. (2021); Suga (2021); Valera (2020), sustentam a tese de um aumento generalizado dos casos de VDFM. Em todos os estudos foi verificado que o isolamento social acarretou algum tipo de consequência na problemática da VDFM, tais como: agravamento das lesões das vítimas de VDFM (Nittari et al., 2021) e aumento do número de denúncias (Abuhammad (2020); Espinosa-Bejarano (2020); Bradbury-Jones \& Isham (2020); Graham-Harrison et al. (2020); Noman et al. (2021); Suga (2021); Valera (2020)).

Diante desse cenário, que poderá se exacerbar ainda mais com o agravamento da pandemia, faz-se prioritário compreender os riscos envolvidos na efetividade das políticas públicas desenvolvidas, para melhor cumprir a legislação em vigência. A Constituição Federal de 1988, a Lei 11.340/2006 (Lei Maria da Penha) e a Convenção Interamericana para Prevenir, Punir e Erradicar a Violência contra a Mulher (Convenção de Belém do Pará) são dispositivos legais que consolidam o papel do Estado no desenvolvimento e consolidação de políticas públicas específicas para o combate à VDFM no Brasil.

$\mathrm{O}$ estudo contribui por descrever o caso de um estado brasileiro que apresentou resultados inversos com a redução de casos registrados de VDFM. Apesar da redução descrita, sustenta-se, como principal pressuposto, que o afastamento da mulher de sua rede de apoio (família, amigos, delegacias, postos de saúde) em Sergipe tem gerado maior dificuldade para a vítima efetuar a denúncia, tanto por conta da presença do agressor no ambiente doméstico, quanto pelo risco de contaminação.

Poucos são os estudos que lançam luz sobre a problemática em Sergipe, no período conturbado da pandemia pela Covid-19. Santos et al. (2020) verificaram que o ciclo da violência no relacionamento abusivo é um dos fatores que fazem com que a vítima permaneça no relacionamento violento e que a cultura machista naturaliza o comportamento abusivo e controlador do companheiro agressor. $O$ trabalho desenvolvido por Jorge et al. (2020), que apresentou o cenário de diminuição de denúncias de VDFM no Estado, não discute a questão das políticas públicas de combate à VDFM. Em uma perspectiva prática, o estudo fornecerá dados à rede de enfrentamento e apoio à VDFM do Estado de Sergipe, subsidiando a adoção de medidas que elevem a efetividade das ações que têm sido desenvolvidas em Sergipe durante o período de isolamento social.

A pesquisa, de caráter qualitativo, baseou-se na análise de dados primários e secundários. Para tanto, optou-se pelo método estudo de caso único, pois conforme preconiza Gil (2021), um único objeto - gestão de riscos em políticas públicas de combate à VDFM em Sergipe - foi estudado em profundidade com o objetivo de se obter um conhecimento amplo e detalhado acerca do mesmo. Para tanto, foi realizado um levantamento dos instrumentos de gestão de riscos que a rede de apoio e enfrentamento à VDFM utiliza como política pública. Esses dados foram obtidos através de pesquisa inicial 
de fontes secundárias, tais como: documentos oficiais do governo, legislação vigente, informações disponíveis em sites governamentais, anuários de gestão, informativos e artigos científicos acerca do tema.

O artigo é dividido em cinco seções: esta introdução, referencial teórico no qual elenca os seguintes tópicos: a VDFM no contexto da pandemia por Covid-19, políticas públicas de combate à VDFM, gestão de riscos como política pública contra a VDFM; procedimentos metodológicos; análise dos resultados e considerações finais.

\section{A VDFM NO CONTEXTO DA PANDEMIA POR COVID-19}

A VDFM não é um fenômeno recente, sendo reflexo de uma sociedade patriarcal e sexista, na qual a ausência de respeito pela figura feminina e a impunidade aos homens sempre estiveram presentes nas relações intrafamiliares. Ela possui raízes profundas, assumindo diversas formas e conteúdo, fazendo-se presente em diferentes culturas e classes sociais. (Blay, 2003; Melo et al., 2020). De acordo com o Art. $5^{\circ}$ da Lei Maria da Penha, se configura como VDFM qualquer ação ou omissão baseada no gênero que cause morte, lesão, sofrimento físico, sexual ou psicológico e dano moral ou patrimonial (LEI No 11.340, DE 7 DE AGOSTO DE 2006, 2006). Assim, compreendese a VDFM como um problema social, multifatorial e com alto grau de complexibilidade (Melo et al., 2020).

Dentro dessa problemática, o termo feminicídio tem sido usado constantemente para se referir às mortes violentas sofridas por mulheres, em razão do gênero. Ou seja, mortes que foram motivadas por sentimentos de menosprezo e discriminação dos homens em relação às mulheres (Canal, Alcantara, \& Machado, 2019). Na legislação brasileira, o termo foi institucionalizado através da Lei No 13.104/2015 - Lei do Feminicídio.

Essa realidade tem sido agravada dentro do contexto de isolamento social gerada pela pandemia de COVID-19. As ações adotadas para combater podem gerar uma elevação da violência doméstica e do feminicídio (ONU, 2020). A violência doméstica aumentou em todo o mundo devido às medidas de isolamento social, que implicam em mulheres permanecendo em seus lares juntamente com os agressores. (Gulati \& Kelly, 2020; ONU, 2020; Peterman et al., 2020). Este fato tem sido associado às alterações bruscas no cotidiano das famílias, geradas pelas medidas restritivas para controle de disseminação da Covid-19; uma vez que tal situação estabelece novas situações de estresse, levando a ataques de violência (Abuhammad, 2020; Espinosa-Bejarano, 2020; Melo et al., 2020). Há indícios de que mulheres, após serem violentadas por seus parceiros, não estão conseguindo denunciar de maneira efetiva, uma vez que estão reclusas em seus lares (Peres, 2020). Esses dados revelam expressivamente questões sociais associadas à misoginia e desigualdades de gênero (Lobo, 2020).

Um número expressivo de vítimas tem dificuldade em acessar os canais de apoio alternativos, pois os agressores detêm o celular da mulher em seu poder. É válido 
acrescentar que, embora o acesso a novas tecnologias tenha aumentado, as questões socioeconômicas ainda dificultam que mulheres de baixa renda participem dessa realidade, por conta da situação de exclusão digital no país. (Lobo, 2020). Segundo dados levantados pelo Fórum Brasileiro de Segurança Pública - FBSP, desde o início do isolamento observa-se em diversos estados uma redução no registro de crimes contra a mulher, com exceção do mais letal: o feminicídio. Segundo o Fórum, este fato se constitui em um indicativo de que as mulheres estão enfrentando maiores dificuldades em denunciar. Em consonância a esta constatação, o FBSP tem evidenciado mensalmente uma elevação no número de feminicídios e/ou homicídios em diversos estados (FBSP, 2020; Jorge et al., 2020). Talvez se faça necessário projetar um novo foco nas políticas públicas de combate à VDFM.

Bradbury $\square$ Jones \& Isham (2020) destacam que os governos em todo o mundo solicitam à população que desempenhem seu papel individual no combate à Covid-19, permanecendo em casa; mas uma consciência crítica do que esse fato significa para muitas mulheres e crianças também é importante. Nesse sentido, Espinosa-Bejarano (2020) afirma que o sistema de dominação dos homens contra as mulheres persiste em todos os níveis sociais; por isso, é necessário que haja estratégias de combate a novos casos de VDFM. Dessa forma, considerando o período de isolamento social, é fundamental que o Estado implemente políticas públicas que atendam às vítimas de todas as camadas sociais, uma vez que as mulheres mais pobres possuem maiores restrições de acesso aos meios de comunicação (Lobo, 2020). Também deve-se considerar que embora o aumento de casos de VDFM não possua relação com a doença em si, o isolamento tem sido apontado como um fator potencializador dessa problemática (Abuhammad, 2020; Lobo, 2020; Peterman et al., 2020; Valera, 2020).

\section{POLÍTICAS PÚBLICAS DE COMBATE À VDFM}

A política pública é um conceito abstrato que se materializa através de ferramentas concretas, tais como: leis, programas, campanhas, decisões judiciais, impostos, entre outros. O objetivo de uma política pública é o enfrentamento, mitigação e até mesmo a resolução do problema público. (Secchi, 2017). Nesse sentido, já foram implementadas diversas políticas públicas que têm colaborado na mitigação da VDFM. A Constituição Federal de 1988 representa um marco no processo de estabelecimento dos direitos das mulheres no Brasil. O Artigo 226 trata nominalmente a violência, prevê o papel de proteção do Estado em relação à família, assim como a proteção de seus membros, especialmente em seu parágrafo oito (BRASIL, 1988).

Além da Constituição Federal, há outros dispositivos legais que fortalecem essa proteção, tais como a Lei № 11.340/2006 - Lei Maria da Penha (LMP); e a Convenção Interamericana para Prevenir, Punir e Erradicar a Violência contra a Mulher - "Convenção de Belém do Pará” (Aguiar, D’Oliveira, \& Schraiber, 2020). Porém, a promulgação da lei 
não implica em sua pronta efetividade: apesar de sua relevância no combate à VDFM, ela não se deu de forma homogênea no país, uma vez que a eficácia legislativa depende da implementação de serviços acessórios de proteção às mulheres, que se deu de maneira desigual no território (Lisboa, 2014). Sobre isso, Waiselfisz (2015) afirma que a judicialização não é somente a criminalização da VDFM formal estabelecida por lei, mas também a consolidação de estruturas específicas que possibilitem a mobilização do aparelho policial e/ou jurídico para a proteção das vítimas e/ou punição dos agressores.

Durante o isolamento social, o acesso aos serviços de apoio, como postos de saúde e delegacias, é reduzido - seja por conta da prioridade que os hospitais e postos de saúde dão aos pacientes diagnosticados com Covid-19 ou pela dificuldade que a vítima tem em se deslocar até o local (Lobo, 2020; Nittari et al., 2021; Okabayashi et al., 2020). Para contornar essa situação, o Ministério da Mulher da Família e dos Direitos Humanos desenvolveu plataformas digitais dos canais de atendimento da Ouvidoria Nacional de Direitos Humanos, tais como o aplicativo Direitos Humanos BR e o site ouvidoria.mdh. gov.br (Okabayashi et al., 2020; Vieira, Garcia, \& Maciel, 2020). Porém, essa medida encontra um entrave: no período de isolamento social, os agressores possuem mais controle sobre a vítima.

\subsection{Gestão de Riscos como Política Pública contra a VDFM}

O enfrentamento à VDFM no contexto de pandemia, engloba a necessidade de compreender de que forma a pandemia é um fator de risco nesse tipo de violência. Apesar da violência contra as mulheres ser uma realidade que existe independente do isolamento social, estudos tem apontado que essa problemática é agravada pelo momento atual (Abuhammad, 2020; Bradbury-Jones \& Isham, 2020; Graham-Harrison et al., 2020; Espinosa-Bejarano, 2020; Nittari et al., 2021; Noman et al., 2021; Suga, 2021; Valera, 2020). Nesse sentido, a gestão de riscos torna-se imprescindível, conforme afirmou Lobo (2020): "É sobre essa pandemia de violência doméstica, um surto longevo, cabe dizer, cuja responsabilidade é de todos nós, que também devemos nos preocupar e buscar soluções".

A gestão de riscos que visa a proteção da mulher na Segurança Pública, no Poder Judiciário e no Ministério Público está centrada no pedido e deferimento de Medida Protetiva de Urgência. Outras ações de gestão de risco são o encaminhamento da vítima para atendimento realizado pela equipe psicossocial e para outros órgãos, uma vez que os atendimentos psicossocial, de saúde e socioassistencial podem ajudar a diminuir riscos. Por sua vez, as medidas centrais de gestão de risco nos serviços de saúde e socioassistencial são o encaminhamento para delegacias e casas-abrigo. Frequentemente, somente a partir da negativa das mulheres à oferta de abrigamento é que outras medidas são buscadas (Tavares \& Medeiros, 2015).

Somando-se às medidas supracitadas, foi implantado por meio de Resolução Conjunta do Conselho Nacional de Justiça (CNJ) e do Conselho Nacional do Ministério Público 
(CNMP) o Formulário Nacional de Avaliação de Risco (Brasil, 2020). Este formulário é um importante instrumento na prevenção e enfrentamento à VDFM, pois permite diagnosticar e identificar a situação de risco em que a vítima se encontra em seu primeiro atendimento; possibilitando assim a adoção de medidas ou decisões para evitar a reincidência da violência (Sommariva \& Hugill, 2020). Esse trabalho conjunto do CNJ e CNMP resultou na publicação da Lei que instituiu o Formulário Nacional de Avaliação de Risco, a ser aplicado às mulheres vítimas de violência doméstica e familiar (Brasil, 2021).

Estudos da literatura internacional classificam a atividade de prevenção da violência doméstica em três níveis: prevenção primária, secundária e terciária (Heise, 2011; Krug et al., 2002; Our Watch, 2021). As políticas de prevenção primária são desenvolvidas para a população como um todo, e possui como foco as causas primárias da VDFM causas relacionadas às percepções estereotipadas sobre os papéis sociais entre homens e mulheres, que normalizam a violência de gênero (Ávila, 2017). A prevenção secundária objetiva alcançar indivíduos que estão em uma situação de risco acima da média, e impedir que estes sofram ou pratiquem a violência doméstica; ou ainda se relaciona a intervenções subsequentes à violência para evitar o aumento do nível da violência. A prevenção terciária envolve ações de longo prazo para mitigar as consequências da violência - como os programas de apoio à vítima e de responsabilização do agressor, além das respostas pelo sistema judiciário (Pasinato, Machado, \& Ávila, 2019).

Por fim, ante ao exposto, faz-se necessário demonstrar, em síntese, os principais 174 tópicos explanados, os respectivos autores e os conceitos assumidos para a presente pesquisa. São eles: se configura como VDFM qualquer ação ou omissão baseada no gênero que cause morte, lesão sofrimento físico, sexual ou psicológico e dano moral ou patrimonial (Brasil, 2006); a VDFM é um problema social, multifatorial e com alto grau de complexibilidade (Melo et al., 2020); a judicialização da VDFM não é somente a criminalização da VDFM formal estabelecida por lei, mas também a consolidação de estruturas específicas que possibilitem a mobilização do aparelho policial e/ou jurídico para a proteção das vítimas e/ou punição dos agressores (Waiselfisz, 2015); durante o isolamento social, o acesso aos serviços de apoio, tais como postos de saúde e delegacias, são reduzidos - seja por conta da prioridade que os hospitais e postos de saúde dão aos pacientes diagnosticados com Covid-19 ou pela dificuldade que a vítima tem em se deslocar até o local (Lobo, 2020; Nittari et al., 2021; Okabayashi et al., 2020).

\section{PROCEDIMENTOS METODOLÓGICOS}

O presente estudo possui caráter qualitativo e descritivo, nos critérios definidos por Gil (2021). Além disso, pode ser caracterizado como um estudo de caso único. A modalidade é aplicável quando se evidencia um contexto peculiar (Yin, 2015). Neste caso, admite-se como contexto peculiar a rede de apoio governamental de combate à VDFM. Por questões de conveniência e acessibilidade dos pesquisadores (Sampieri, Collado, 
\& Lucio, 2006), foi delineado como sujeito da pesquisa a Delegacia de Atendimento à Mulher - DEAM, dentro do Departamento de Atendimento a Grupos Vulneráveis - DAGV. Segundo fluxo da Rede de Enfrentamento/Atendimento disponibilizado no portal da Coordenadoria da Mulher do Tribunal de Justiça de Sergipe (https://www.tjse.jus.br/ portaldamulher/fluxogramas), todos os canais de atendimento de casos de violência contra a mulher são direcionados para a DEAM.

Para a realização do estudo, foi elaborado um protocolo nos moldes de Yin (2015) contendo: visão geral do estudo de caso e finalidade do protocolo; procedimentos de coleta de dados; questões de estudo de caso e guia para relatório do estudo de caso, e o roteiro semiestruturado para condução das entrevistas, ambos elaborados a partir da revisão da literatura e do referencial teórico.

Quadro 1. Protocolo de estudo de caso

\begin{tabular}{|c|c|}
\hline Elemento & Caracterização \\
\hline $\begin{array}{l}\text { Visão geral do estudo } \\
\text { de caso e finalidade do } \\
\text { protocolo }\end{array}$ & $\begin{array}{l}\text { O estudo de caso objetiva analisar os riscos de efetividade das políticas públicas de } \\
\text { enfrentamento à VDFM, em tempos de pandemia; e propor melhorias/recomendações } \\
\text { após análise dos dados. O protocolo foi elaborado para orientar o pesquisador nas } \\
\text { etapas necessárias para o desenvolvimento da pesquisa, mantendo assim o foco sobre } \\
\text { tópico do estudo de caso. }\end{array}$ \\
\hline $\begin{array}{l}\text { Procedimentos de coleta } \\
\text { de dados - fontes de } \\
\text { evidência }\end{array}$ & $\begin{array}{l}\text { 1. Arquivos de inquéritos policiais disponibilizados pelo Departamento de } \\
\text { Atendimento a Grupos Vulneráveis; } \\
\text { 2. Entrevistas semiestruturadas com servidores da DEAM e Delegacia Plantonista. }\end{array}$ \\
\hline $\begin{array}{l}\text { Questões de estudo de } \\
\text { caso }\end{array}$ & $\begin{array}{l}\text { 1. Como está organizada a rede de apoio e enfrentamento à VDFM em Sergipe? } \\
\text { 2. Como foram aplicadas as políticas públicas de enfrentamento à VDFM } \\
\text { adotadas pelo governo sergipano, durante a pandemia de Covid-19? } \\
\text { 3. Que dados merecem maior atenção no contexto da violência contra a mulher } \\
\text { em Sergipe, ao longo da pandemia? } \\
\text { 4. Como a pandemia de Covid-19 impactou na aplicação de políticas públicas de } \\
\text { enfrentamento à VDFM em Sergipe? } \\
\text { 5. Como as políticas públicas de combate à VDFM pelo governo sergipano } \\
\text { podem ser melhoradas/adaptadas? }\end{array}$ \\
\hline $\begin{array}{l}\text { Guia para relatório do } \\
\text { estudo de caso }\end{array}$ & $\begin{array}{l}\text { Deve ser elaborado de forma clara e objetiva, detalhando-se as informações obtidas } \\
\text { através de análise documental e referencial teórico acerca da temática. }\end{array}$ \\
\hline
\end{tabular}
Fonte: Adaptado de Yin (2015)

Um estudo de caso pode ser baseado em diversas fontes de evidências (Yin, 2015). Para esse trabalho foram adotadas três fontes: documental-documentos oficiais e inquéritos; entrevistas em profundidade, com profissionais envolvidos com o atendimento na DEAM. Assim, analisaram-se documentos oficiais emitidos pelo Governo de Sergipe, notícias de sites de cunho jornalístico, dados e informações disponíveis em sites governamentais, relatórios de gestão de órgãos integrantes da rede de apoio e enfrentamento, informativos e reuniões online de órgãos governamentais transmitidas através das mídias sociais. Também foi realizada coleta in loco dos arquivos de inquéritos policiais da DAGV referentes à violência doméstica em Aracaju, no período de maio a julho de 2020. Esse recorte se justifica por conta dos dados apontados no trabalho de Jorge et al. (2020), que indicaram uma redução de registros de VDFM nesse período, ainda que o expediente presencial das delegacias e demais canais de denúncia tenham sido mantidos, o que reforça o pressuposto adotado 
no atual estudo: a vítima tem dificuldades em efetuar a denúncia pelas especificidades do contexto de pandemia - afastamento da rede de apoio e enfrentamento e maior controle do agressor dentro do ambiente doméstico.

Por esse caminho, foram coletados dados por meio de entrevistas semiestruturadas aplicadas a três escrivães e uma delegada que atuam no DAGV, seja no atendimento regular da DEAM ou nos plantões. Sobre o instrumento semiestruturado utilizado para entrevista em profundidade, este foi dividido em cinco blocos: perfil - nome, função, setor e tempo de atuação; fatores favorecedores ou comprometedores para atuação da rede de apoio e enfrentamento - atendimento inicial, formulário nacional e inquéritos; causas e consequências dos fatores identificados; instrumentos de gestão de riscos; subsídios para construção de políticas de gestão de risco de violência doméstica contra a mulher. Os entrevistados foram identificados pela letra E (de E1 a E4), para manter o sigilo nas entrevistas.

Após os procedimentos de coleta dos dados foram efetuadas as transcrições, perfazendo 26 páginas. Posteriormente, foi realizada uma análise do conteúdo, de maneira inspirada ao método desenvolvido por Bardin (2016): realizou-se uma pré-análise, delineando-se os textos e as falas que aparecem mais conexos com as variáveis centrais da pesquisa, - "Atendimento à vítima no contexto de pandemia", "aumento da violência na pandemia", "desistência da denúncia", "reincidência da violência", "dependências das vítimas", "normalização da violência", "dificuldade no andamento do inquérito", "efetividade 176 dos instrumentos de gestão de risco" e "proposição de melhorias" - o que reduziu o volume para 13 páginas. Identificaram-se as ideias centrais e foi realizada uma revisão na categorização instituída, selecionando os dados mais significativos para formar "categorias". Com base nessas categorias, foram extraídas subcategorias, formando proposições isoláveis. A análise foi dividida em quadros, de forma a relacionar os resultados com os objetivos do estudo. Isso favoreceu o debate acerca das percepções dos entrevistados, ao formar 12 categorias e 20 subcategorias a partir da codificação das falas.

Acerca dos documentos investigados, foram percorridas as duas etapas iniciais (préanálise e análise), porém decidiu-se utilizar diretamente os conteúdos mais relacionados ao longo das análises.

\section{ANÁLISE DOS RESULTADOS}

Gestão do Risco, segundo a NBR ISO 31000 (ABNT, 2018), é parte de todos os serviços de uma organização, incluindo um entrosamento com todas as partes interessadas, considerando fatores internos e externos, comportamento humano e demais questões culturais. ALMP é um marco político nesse quesito, ao trazer gerenciamento de risco quando estabelece, por exemplo, um rol de medidas protetivas de urgência visando prevenir a VDFM (Pasinato, Machado, \& Ávila, 2019). 
Quadro 2. Dimensões do atendimento

\begin{tabular}{|c|c|c|}
\hline Categorias & Subcategorias & Falas \\
\hline \multirow[t]{3}{*}{$\begin{array}{l}\text { Atendimento à } \\
\text { vítima }\end{array}$} & Expediente presencial & $\begin{array}{l}\text { (...) nós fomos o único órgão praticamente junto com a saúde que } \\
\text { ficamos } 24 \text { h funcionando presencial (...) (E2) } \\
\text { (...) a gente faz uma triagem fora da delegacia, né? Por questões de } \\
\text { segurança mesmo (...) (E1) }\end{array}$ \\
\hline & $\begin{array}{l}\text { Dificuldade para } \\
\text { abertura de BO online }\end{array}$ & $\begin{array}{l}\text { (...) houve uma certa dificuldade para o acesso virtual, o acesso } \\
\text { remoto, (...) elas ficam prejudicadas em acessar quando estão } \\
\text { próximas aos agressores (...) (E2) }\end{array}$ \\
\hline & Desistência da denúncia & $\begin{array}{l}\text { (...) a pessoa vem para a delegacia... tal... chateada... aí vai narrando... } \\
\text { mas depois passa um dia, passa dois dias, ela quer voltar para o } \\
\text { suposto autor (...) (E3) }\end{array}$ \\
\hline \multirow[t]{3}{*}{ Casos } & $\begin{array}{l}\text { Percepção de aumento } \\
\text { nos casos }\end{array}$ & $\begin{array}{l}\text { Sim, eu percebi isso... que houve um aumento da demanda, } \\
\text { entendeu? (...) eu acho que muitos sem trabalhar, em casa e tal, e aí } \\
\text { talvez os atritos se acentuaram, entendeu? (E3) }\end{array}$ \\
\hline & $\begin{array}{l}\text { Reincidência } \\
\text { escalonamento } \\
\text { violência }\end{array}$ & $\begin{array}{l}\text { Eu costumo dizer que é uma escadinha a violência doméstica, né? } \\
\text { Começa com coisinhas pequenas e vai aumentando, (...) (E1) }\end{array}$ \\
\hline & Busca pela reconciliação & $\begin{array}{l}\text { (...) eu acredito numa cultura de paz, (...) se a mulher tem essa visão } \\
\text { de que esse relacionamento pode ser reatado e que a família pode } \\
\text { ser restaurada (...) deve se insistir nessa situação. Lógico, retirando } \\
\text { os casos graves de violência, de tentativa de feminicídio (...) (E2) }\end{array}$ \\
\hline
\end{tabular}

Fonte: Pesquisa de campo (2021)

Sobre as categorias relacionadas ao atendimento e aos casos às vítimas, emergiram dados importantes. "Dificuldade para abertura de BO online" reforça a afirmação de Lobo (2020), de que apesar do aumento do acesso à novas tecnologias, as mulheres de baixa renda sofrem exclusão digital no país, dificultando o acesso ao atendimento virtual disponibilizado. Apesar disso, conforme exposto por E2, a delegacia da mulher não alterou o expediente presencial durante a pandemia, mas vem realizando triagens dos atendimentos para adentrar na delegacia apenas os casos de VDFM.

As informações obtidas sobre "percepção de aumento dos casos" durante a pandemia divergem da interpretação dos resultados no estudo de Jorge et al. (2020). Ele supôs a dificuldade da vítima em denunciar a agressão sob as vistas do agressor, bem como o temor em contrair COVID-19 no trajeto para a delegacia, uma vez que o referido estudo apontou uma diminuição de $28,7 \%$ nos casos de VDFM em Sergipe, entre março e julho de 2020, em comparação ao mesmo período do ano anterior. A princípio, tal interpretação foi adotada como principal pressuposto do presente estudo. Porém, após análise das informações obtidas por meio das entrevistas, surge uma nova possibilidade: o movimento de denúncias teria aumentado, mas a formalização em inquéritos, diminuído. Esse movimento de denúncias é demonstrado pelo Anuário Brasileiro de Segurança Pública (FBSP, 2021), que registrou em todo o ano de 2020 um aumento de $264,2 \%$ nos atendimentos do 190 sobre casos de violência doméstica em Sergipe, em comparação a 2019. Associada a essa informação, a análise documental de 210 inquéritos revelou que 68 (32,38\%) desses foram abertos mediante auto de prisão em flagrante, enquanto os 142 (67,62\%) restantes foram abertos mediante registro presencial, não havendo inquéritos motivados por outros canais de denúncia, como o disque 180 ou o Boletim de Ocorrência virtual. 
Acerca da subcategoria "desistência da denúncia", emergiu nas entrevistas que existem dificuldades de a vítima em romper vínculos com o seu agressor, existindo diferentes motivações possíveis para isso: medo, vergonha e a sensação de isolamento, de perda de laços sociais e familiares (Ferreira, 2020), ameaças e medo de perda da guarda dos filhos, de não receber a pensão alimentícia, dificultam o rompimento com o ciclo da violência (Paraná, 2018) e a própria pandemia pode estar agravando essa situação.

As informações percebidas na subcategoria "percepção de aumento de casos" convergem com as principais causas apontadas para aumento da VDFM em estudos recentes, como a diminuição da renda familiar, aumento da manipulação do agressor sobre a vítima em razão do maior tempo de convivência e aumento dos níveis de estresse (Marques et al., 2020; Vieira, Garcia, \& Maciel, 2020).

Sobre a "reincidência da violência", esse é outro fenômeno que pode estar recrudescendo durante a pandemia. $O$ isolamento social potencializa a permanência da vítima no ciclo da violência, uma vez que as restrições impostas dificultam as relações de apoio por conta da distância e da impossibilidade e/ou dificuldade de pedir ajuda a membros da família e rede de apoio fora do ambiente onde ocorrem as agressões (Marcolino et al., 2021). É consenso que o nível de violência tende a aumentar durante a relação; e a percepção por parte da mulher de que as relações podem ser restauradas, caso a violência não tenha atingido extremos, existindo um ciclo de violência (Walker, 1979), que pode estar se exacerbando no isolamento.

Nesse grupo de variáveis, emergiram situações que merecem ser consideradas pela gestão de riscos: 1. Dificuldade de acesso das vítimas a atendimento virtual; 2. Aumento nos casos, com redução de inquéritos, o que pode sinalizar que, na pandemia, há riscos de o Estado estar sendo menos efetivo na promoção da segurança pública a esse subgrupo vulnerável; 3. O ciclo de violência pode estar sendo invisibilizado devido ao isolamento.

Quadro 3. Dimensões de causas e consequências da violência

\begin{tabular}{|l|l|l|}
\hline Categorias & Subcategorias & Falas \\
\hline \multirow{2}{*}{ Causas } & $\begin{array}{l}\text { Dependências das } \\
\text { vítimas }\end{array}$ & $\begin{array}{l}\text { (...) dependência financeira, na maioria das vezes. Tem já uma } \\
\text { dependência emocional daquele agressor (...) (E1) }\end{array}$ \\
\cline { 2 - 3 } Consequências & $\begin{array}{l}\text { Naturalização } \\
\text { violência }\end{array}$ & $\begin{array}{l}\text { (...) muitas vezes ela acha que é normal, né? (...) Não é com um } \\
\text { encontro ou dois na delegacia que vai ser desconstruído com a } \\
\text { vítima, de que ela é uma vítima e de que ele é um agressor, né? } \\
\text { (E1) }\end{array}$ \\
\hline andamento do inquérito & $\begin{array}{l}\text { E muitas delas desmentem, né? Dizem que não aconteceu nada } \\
\text { daquilo. (E1) } \\
\text { (...) quando a vítima desiste depois por algum fator, ela realmente } \\
\text { não ajuda em nada. A gente precisa de algum dado, um telefone } \\
\text { de alguém, endereço... (E4) }\end{array}$ \\
\hline
\end{tabular}

Fonte: Pesquisa de campo (2021)

Emergiram do campo aspectos que se relacionam às causas e as consequências da violência. Sobre as primeiras, Carneiro et al. (2017), destacam que no caso da "dependência das vítimas" há alguns fatores que favorecem a continuidade de uma relação violenta, 
como a existência de submissão, humilhação, dependência financeira e emocional. Já a cultura da "naturalização da violência", faz com que as mulheres não a reconheçam e, muitas vezes, até se culpem pelas agressões e justifiquem o agressor, de forma a protegêlo (Matosinhos, 2018).

No contexto das consequências, foi relatado que muitas vítimas tentam se retratar após a denúncia, inocentando o agressor ou, ainda, "não cooperando com o andamento do inquérito". As vítimas até desistem de registrar denúncia ou de procurar algum ente da rede de apoio e enfrentamento, pois elas desejam acabar com a violência, mas não com a relação, acreditando que o agressor pode mudar (Saffioti, 2015).

Depreende-se desse grupo de variáveis que existe um contexto de construção social no risco da violência contra a mulher, que pode estar sendo exacerbado durante a pandemia. Como reflexo possível, tem ocorrido um processo de redução no número de inquéritos, conforme já discutido.

Quadro 4. Dimensão da efetividade dos instrumentos de gestão de riscos

\begin{tabular}{|c|c|c|}
\hline Categorias & Subcategorias & Falas \\
\hline $\begin{array}{l}\text { M e d i d a s } \\
\text { Protetivas de } \\
\text { Urgência }\end{array}$ & Processo estruturado & $\begin{array}{l}\text { (...) o delegado faz o pedido, o juiz defere a medida protetiva, } \\
\text { depois no inquérito nós vamos ouvir o suposto autor, vamos colher } \\
\text { testemunhas, vamos saber se o caso realmente foi daquela forma, aí } \\
\text { agora remete esse inquérito para a justiça, entendeu? (E3) }\end{array}$ \\
\hline \multirow{3}{*}{$\begin{array}{lllll}\text { A } & p & o & i & o \\
\text { psicossocial } & \end{array}$} & Estrutura deficitária & $\begin{array}{l}\text { (...)nós temos apenas uma assistente social e a demanda é altíssima. } \\
\text { Nossa psicóloga está afastada (...) eu acho que é um dos pontos } \\
\text { frágeis do DAGV ainda é esse, o acolhimento psicossocial. (E2) }\end{array}$ \\
\hline & $\begin{array}{l}\text { Desinteresse } \quad \text { pelo } \\
\text { atendimento }\end{array}$ & $\begin{array}{l}\text { (...) a própria vítima não quer esse acompanhamento, ela quer } \\
\text { resolver aquele problema momentâneo, entendeu? (...) Eu mesmo } \\
\text { não vejo a vítima pedindo acompanhamento... dificilmente. (E3) }\end{array}$ \\
\hline & $\begin{array}{l}\text { Heterogeneidade entre } \\
\text { localidades }\end{array}$ & $\begin{array}{l}\text { No interior (...) são menos pessoas, às vezes a própria assistente } \\
\text { social entrava em contato com a delegacia para dizer que a vítima } \\
\text { tinha saído (...) Aqui existe uma conversa entre os órgãos, mas não } \\
\text { sobre cada vítima, (...) (E1) }\end{array}$ \\
\hline asas-abrigo & $\begin{array}{l}\text { Falta de interesse pelo } \\
\text { acolhimento }\end{array}$ & $\begin{array}{l}\text { A casa-abrigo é um ambiente bem restrito (...) isso faz muitas } \\
\text { desistirem. (...) quem é daqui que tem família aqui, normalmente } \\
\text { acaba indo para a casa de família ou amigos (...). (E1) }\end{array}$ \\
\hline $\begin{array}{l}\text { Fo r m u l á r i o } \\
\text { Nacional de } \\
\text { Avaliação } \\
\text { Riscos }\end{array}$ & $\begin{array}{l}\text { Coleta da realidade de } \\
\text { cada caso }\end{array}$ & $\begin{array}{l}\text { (...) com esse formulário a gente tem condições de averiguar } \\
\text { realmente, como é a vida dessa mulher, o quanto de violência ela } \\
\text { vem sofrendo, e também dar suporte para uma atuação do serviço } \\
\text { social da rede e dos serviços de psicologia (...) (E2) }\end{array}$ \\
\hline $\begin{array}{l}\text { Capacitação do } \\
\text { pessoal }\end{array}$ & Reciclagens frequentes & $\begin{array}{l}\text { Eles estão sempre passando por curso de capacitação e } \\
\text { aperfeiçoamento para que esse serviço de assistência às vítimas e } \\
\text { aos vulneráveis seja o melhor possível (...) não entra ninguém sem } \\
\text { passar por curso de capacitação em atendimento a grupo vulnerável } \\
\text { (...) (E2) }\end{array}$ \\
\hline
\end{tabular}

Fonte: Pesquisa de campo (2021)

Nesse conjunto de variáveis, emergiram dados sobre a efetividade das ferramentas relacionadas ao risco de violência contra a mulher. Sobre a "Medida Protetiva de Urgência", essa é utilizada no ato da denúncia, de forma a evitar qualquer risco de ocorrer uma violência letal ou com maiores danos. Isso possibilita ao inquérito que, posteriormente, 
prossiga em seus procedimentos, sendo, ao final, encaminhado ao processo judicial competente. As medidas protetivas foram mais um instrumento de gestão de riscos trazido pela Lei Maria da Penha. Tal lei é considerada uma das mais evoluídas no mundo, no tocante ao enfrentamento à VDFM (Bandeira \& Almeida, 2014). A pandemia de COVID-19, aparentemente, não restringiu a atuação da Polícia Civil no encaminhamento dos pedidos ao judiciário.

Sobre a "estrutura de apoio psicossocial" em Aracaju, essa é percebida como insuficiente, sendo "um dos pontos frágeis do DAGV". Além disso, foi ressaltado que após a resolução do "problema momentâneo", a vítima geralmente não tem interesse no acompanhamento psicossocial contínuo. Assim, é fundamental que durante a COVID-19 a rede de apoio e enfrentamento seja fortalecida, com o aumento da capacidade para o atendimento clínico e psicossocial para pessoas vítimas de estupro, por exemplo (Melo et al., 2020). Se houver a mitigação desse primeiro impasse, a continuidade do atendimento seria incentivada com maior facilidade.

Emergiu, também, que existe "heterogeneidade entre cidades", sinalizando que nos municípios do interior há maior aproximação entre o apoio psicossocial e a vítima. Essa realidade já foi discutida anteriormente por Cerqueira et al. (2015), ao apontar que a efetividade dos instrumentos trazidos pela LMP não se deu de forma homogênea no país, uma vez que a sua eficácia depende diretamente da implementação de diversos serviços de proteção às mulheres nas localidades.

A categoria "casa-abrigo" também reflete uma falta de interesse das vítimas: por ser um ambiente "restrito", muitas vítimas têm preferência por ficarem abrigadas na "casa de família ou amigos". Um ponto que reforça essa percepção é a análise documental realizada no presente estudo: dos 210 inquéritos no período analisado, apenas 6 tiveram pedido de casa-abrigo. Dentre esses 6 inquéritos, há diferentes tipos de violência - 2 de ameaça, 1 de ameaça e vias de fato, 1 de injúria e lesão corporal dolosa e 2 de lesão corporal dolosa; logo supõe-se que o tipo de violência sofrida não possui ligação com o interesse no abrigo, mas sim com o fato da vítima ter ou não outro local onde se sinta segura. Em estudo realizado por Oliveira, Machado, \& Lima (2020), foi relatado que houve uma diminuição de 88,2\% no número de mulheres acolhidas em uma casa-abrigo de Manaus, no período compreendido entre janeiro e maio de 2020, se comparado ao ano anterior. Pode-se supor nisso que a pandemia também influencie no interesse da vítima em ser acolhida.

Sobre o "Formulário Nacional de Avaliação de Riscos", emergiu como instrumento formal importante para identificação de riscos nos casos de violência doméstica. Esse formulário auxilia na análise dos casos de VDFM subsidiando o diagnóstico e identificação da intervenção cabível na situação (Prestes, 2021). Tal diagnóstico pode evitar uma reincidência da violência, pois possibilita uma intervenção da rede de apoio e enfrentamento em tempo hábil, através da avaliação do risco e identificação dos possíveis fatores que colaboram para que a agressão ocorra novamente (FRA, 2014). Esse documento mostrase crucial para a prevenção, pois possibilita intervenções para mitigar ou evitar eventos de 
risco, encaminhando cada caso para os órgãos mais adequados da rede de enfrentamento (Ávila, 2018).

Finalmente, sobre capacitação, há "reciclagens frequentes". Um questionamento importante é se isso tem sido direcionado à situação social conexa com a pandemia, pois o enfrentamento à VDFM no contexto da pandemia não deve se limitar ao acolhimento das denúncias. É necessário que haja um trabalho integrado com capacitação dos trabalhadores da saúde para identificar situações de risco, de modo a não indicar o isolamento doméstico nesses casos, e a expansão e o fortalecimento das redes de apoio e enfrentamento (Vieira, Garcia, \& Maciel, 2020). Nesse sentido, fica evidente a necessidade de capacitações também para os trabalhadores do atendimento inicial à vítima de VDFM, levando em consideração as especificidades da situação pandêmica.

Nesse conjunto de categorias é possível apontar aspectos importantes, que devem ser considerados na gestão dos riscos: 1. A medida protetiva tem sido uma ferramenta de prevenção ao risco mais bem percebida que o acompanhamento psicossocial pelos profissionais envolvidos no atendimento na Delegacia da Mulher; 2. Nas capitais, a relação impessoal, a baixa adesão ao apoio psicossocial e o uso reduzido da casa-abrigo, sinalizam que a política de prevenção ao risco precisa ser revista. A busca pela resolução momentânea e a deficiência da rede podem estar tendo outros desdobramentos, a exemplo da saúde mental, ampliando a emergência do atendimento psicossocial (Campos, Tchalekian, \& Paiva, 2020), que na pandemia tem sido comprometido; 3. O Formulário Nacional de Avaliação de Riscos oferta diagnóstico que previne reincidência da violência e apoia todo o trabalho da rede de apoio e enfrentamento; 4. Capacitações frequentes podem possibilitar maior identificação de situações de risco no atendimento, sobretudo na pandemia.

Quadro 5. Dimensão dos gargalos e propostas de aprimoramentos das políticas

\begin{tabular}{|c|c|c|}
\hline Categorias & Subcategorias & Falas \\
\hline $\begin{array}{l}\text { Ampliar a } \\
\text { abrangência do } \\
\text { formulário }\end{array}$ & $\begin{array}{l}\text { Coletar casos de } \\
\text { outros vínculos com a } \\
\text { vítima }\end{array}$ & $\begin{array}{l}\text { (...) ele é muito direcionado para violência marital (...) mas é } \\
\text { extremamente deficiente, eu diria até que nem serve. (...) para } \\
\text { violência ou outros tipos de violência (...) deveria existir outro } \\
\text { formulário de risco para outras situações de vínculo afetivo, né? (E1) }\end{array}$ \\
\hline \multirow{2}{*}{$\begin{array}{l}\text { Infraestrutura da } \\
\text { delegacia }\end{array}$} & $\begin{array}{ll}\text { Necessidade de } & \text { de } \\
\text { aperfeiçoamento } & \end{array}$ & $\begin{array}{l}\text { A estrutura física também pode ser um pouco melhorada com } \\
\text { uma sala específica para o acolhimento dessa mulher vítima, } \\
\text { principalmente as mulheres vítimas de abusos sexuais, nós não } \\
\text { temos, a gente deseja muito dar o melhor pra sociedade, pra mulher } \\
\text { vítima, pra mulher revitimizada. (E2) }\end{array}$ \\
\hline & Aumento do efetivo & $\begin{array}{l}\text { (...)precisa de mais profissionais, né? Precisa... é em toda a polícia: para } \\
\text { escrivão, agente, para tudo. Então, né... na questão de assistente social } \\
\text { e psicólogo, precisa de mais pessoas para atendimento, né? (E3) }\end{array}$ \\
\hline Colaboração & $\begin{array}{l}\text { Entes da rede de apoio } \\
\text { e enfrentamento }\end{array}$ & $\begin{array}{l}\text { (...) foge um pouco da nossa função aqui de polícia, realmente a } \\
\text { gente não acompanha muito essa parte, mas a rede é para dar toda } \\
\text { assistência psicológica e social à mulher que está na situação de } \\
\text { violência (...) (E2) }\end{array}$ \\
\hline
\end{tabular}

Fonte: Pesquisa de campo (2021) 
Os respondentes apresentaram propostas de aprimoramentos, diante dos riscos, a saber: ampliação da abrangência do Formulário Nacional de Riscos, aperfeiçoamento da estrutura física da delegacia e contratação de mais profissionais para a rede de apoio e enfrentamento, em geral. Para além dos aprimoramentos na estrutura física e contratação profissionais, que dependem do planejamento no uso de recursos, otimizando o atendimento aos cidadãos para conferir maior eficiência (Ávila, 2018), faz-se prioritário discutir sobre o formulário.

A versão do Formulário utilizada pelo DAGV no período analisado é oriunda da Resolução do CNJ No 284 de 05/06/2019, que foi atualizada posteriormente através da Resolução conjunta do CNJ e CNMP No 5 de 03/04/2020. Essa atualização ampliou o questionário de 25 para 27 perguntas objetivas, além de adicionar uma nova seção com perguntas subjetivas a serem respondidas pelo profissional que atende a vítima. Isso ocorreu às vésperas da publicação da Portaria da PC/SE No 003/2020, que formalizou a versão de 2019 do Formulário dentro do protocolo de trabalhos do DAGV. Contudo, a sugestão da fala em S17 permanece válida, visto que a nova versão ainda não abrange os novos tipos de relação entre vítima e agressor, conforme sugerido nas entrevistas.

O Formulário é composto por duas partes e quatro blocos: a primeira parte contém informações sobre o histórico de violência, sobre o(a) agressor (a), sobre a vítima e outras informações importantes; e na segunda parte, perguntas descritivas que devem ser preenchidas pelo profissional capacitado. É válido pontuar que o Formulário deve ser aplicado pelo profissional para que este consiga identificar os sinais de violência; avaliar os fatores de risco no Formulário Nacional de Avaliação de Risco e assim possa adotar estratégias para proteger a vítima e impedir a reincidência da agressão; além de monitorar o caso e reavaliar sempre que necessário (Sommariva \& Hugill, 2020). Dessa forma, é imprescindível que o profissional consiga utilizar o formulário em qualquer situação de VDFM, independentemente do tipo de vínculo entre vítima e agressor.

Acerca da categoria "colaboração", a relação entre os atores-chave na rede de apoio e enfrentamento dá sinais que, ao mesmo tempo que há pouca colaboração entre os membros da rede e de restrição aos trabalhos típicos de cada órgão, essa ação integrada deveria ser priorizada, para o enfrentamento à VDFM (Angelim, 2009; Ávila et al., 2014; Ellsberg et al., 2015; Heise, 2011; Michau et al., 2015; Pasinato, 2016). Sugere-se que a Coordenadoria da Mulher passe a atuar considerando a necessidade dessa inter-relação com os demais órgãos da rede.

Com esse último grupo de variáveis, percebe-se que: 1. Propõe-se que o Formulário Nacional de Avaliação de Riscos alcance todas as situações de VDFM, além da conjugal; 2. É preciso aperfeiçoar a estrutura física da Delegacia e contratar mais pessoal; 3 . Um possível gargalo para a administração gerencial é a falta de ação mais integrada entre os atores-chave da rede de apoio e enfrentamento.

Para finalizar, concedendo uma visão geral sobre as dimensões que devem ser levadas em conta na gestão do risco para prevenir a VDFM, elaborou-se a Figura 1 com os dados qualitativos levantados. 
Figura 1. Dados qualitativos sobre as dimensões dos riscos

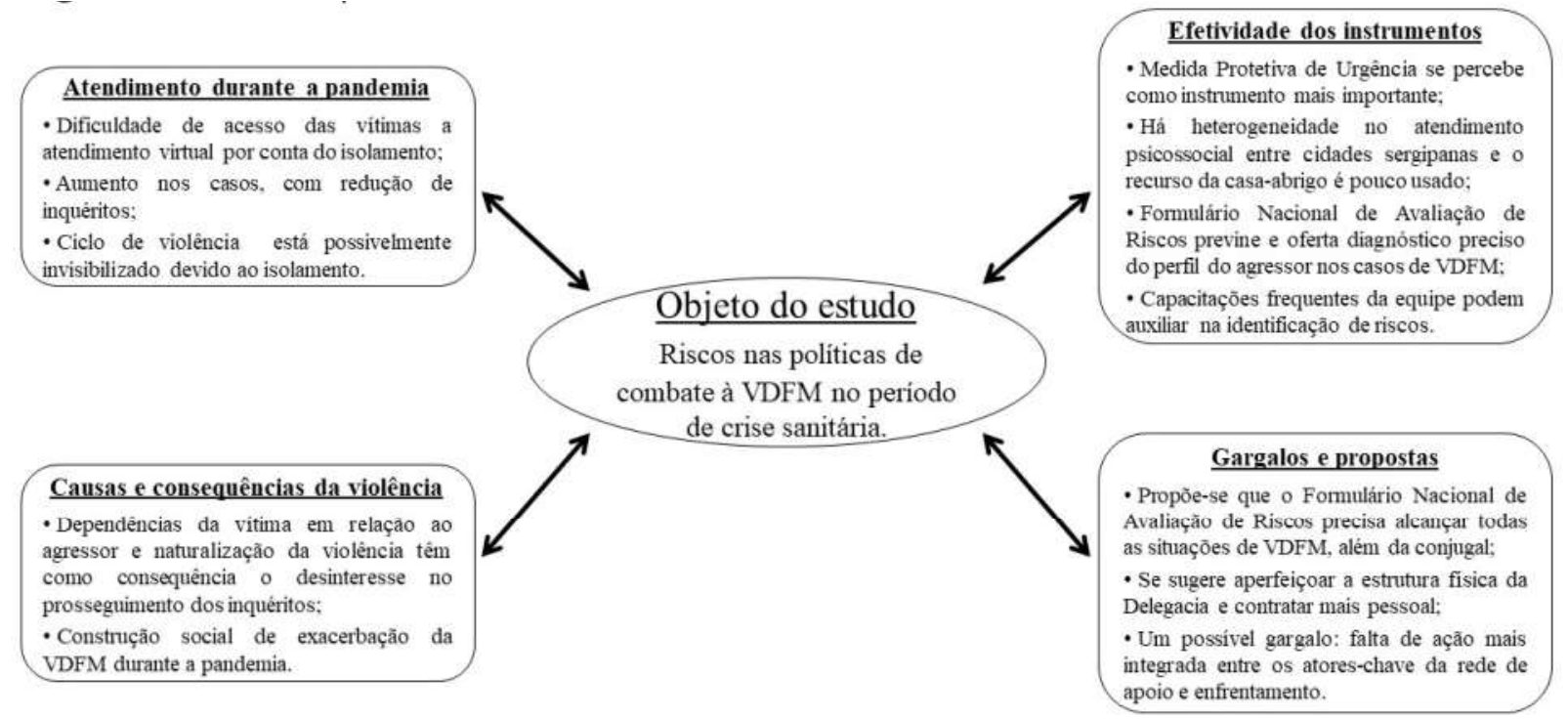

Fonte: Elaborado pelos autores (2021).

\section{CONSIDERAÇÕES FINAIS}

O estudo permitiu analisar as principais dimensões que devem ser consideradas na gestão do risco de VDFM. Como principal achado, pode-se dizer que a pandemia pela Covid-19 agravou problemas pré-existentes, como aumento no caso de violência contra a mulher, dificuldades de atendimento remoto e fragmentação no serviço público no atendimento, confirmando a literatura utilizada (Monteiro, Yoshimoto, \& Ribeiro, 2020). Certamente isso pode ser considerada uma "segunda pandemia", invisível aos olhos da sociedade, cujos efeitos reverberarão ao longo dos próximos anos.

Os achados divergem do principal pressuposto do estudo: afastamento da vítima da rede de apoio, possivelmente causado pela dificuldade em denunciar por conta da presença constante do seu agressor no ambiente doméstico. Isso porque houve percepção de aumento na demanda de atendimentos pelos entrevistados, além de dados fornecidos pelo Anuário Brasileiro de Segurança Pública (FBSP, 2021) que apontam uma elevação do registro de ligações ao 190 sobre VDFM ao longo de todo o ano de 2020. É válido ressaltar que, para denunciar os atos violentos, a vítima precisou se deslocar para a Delegacia em um momento de pandemia, ou se expor ao risco de ligar para o 190 nas ocorrências passíveis de prisão em flagrante.

Como essas percepções não se constituem em fatos comprovados cientificamente no recorte temporal do presente estudo, sugere-se o levantamento de dados mais detalhados, uma vez que são fundamentais para subsidiar estudos multidisciplinares acerca da problemática na cidade de Aracaju, além de otimizar a discussão sobre uma agenda de políticas públicas nessa área.

De maneira prática, os resultados mostram a importância do rol de medidas protetivas de urgência, contidas na LMP, criadas para evitar eventos de extremo risco e ensejando 
um fluxo bem definido para sua efetividade. O preenchimento do Formulário Nacional de Avaliação de Risco confere maior clareza ao protocolo de atuação do Departamento, bem como isonomia nos trabalhos de todos os envolvidos na rede de apoio e enfrentamento à VDFM. As capacitações e reciclagens oferecidas aos delegados, agentes e escrivães promovem melhor acolhimento e compreensão das fragilidades envolvidas no atendimento inicial às vítimas. Essas capacitações e reciclagens também otimizam a eficiência e eficácia dos trabalhos ao remanejar aqueles que não se enquadram nos padrões necessários de atendimento às vítimas. Entretanto, há uma necessidade de evolução no trabalho de conscientização das vítimas e agressores sobre a dinâmica das relações no contexto da VDFM, além de maior compreensão da importância do atendimento psicossocial para reabilitação e mitigação dos riscos, em busca da prevenção da VDFM no atual momento de pandemia pela Covid-19. Essa prevenção garante a efetividade da Lei Maria da Penha. A revitimização da mulher é consequência da falha na gestão de riscos de efetividade. (Fernandes, 2015).

O trabalho contribui ainda com a apresentação de sugestões para mitigar ou evitar riscos, como segue: 1) Ampliação do efetivo policial; 2) Melhorias na estrutura física do DAGV para garantir acolhimento individualizado e sigiloso; 3) Atualização e ampliação do uso do Formulário Nacional de Avaliação de Riscos em VDFM para tipificar relações com vínculos além de conjugais, abrangendo irmãos, mãe e filho, coabitantes na mesma residência, etc.; 4) Atualização de práticas de gestão gerencial entre todos os membros 184 da rede de apoio e enfrentamento; e 5) Atuação multidisciplinar articulada da rede, com comunicação que permita colaboração intersetorial.

O presente estudo aborda o tema da violência doméstica e familiar contra a mulher, sob o aspecto da gestão de riscos. Apesar de haver diversos trabalhos que debatem a questão da prevenção desse tipo de violência, ainda são incipientes os estudos que propõem modelos para gerenciamento de eventos de risco ligados aos processos de trabalho da Polícia Civil.

É fato que houve dificuldade no uso do atendimento virtual, mas que o atendimento presencial teve importância em ser mantido - com protocolos de biossegurança para triagem e acolhimento das denunciantes para abertura dos inquéritos. Também foi percebido um aumento do movimento, em contraste com uma redução no volume de inquéritos abertos, em relação ao mesmo período do ano anterior.

Como limitação da pesquisa, não foi possível estudar a percepção das vítimas sobre a rede de apoio, especialmente sobre o atendimento psicossocial; uma vez que foi relatado que não há interesse no serviço de forma contínua. Nesse sentido, sugerese que trabalhos futuros investiguem isso de forma mais aprofundada e sobre a atuação da Coordenadoria da Mulher após a entrega dos inquéritos ao Tribunal de Justiça de Sergipe. A adoção do estudo de caso como método qualitativo para a pesquisa de campo, em geral, também limita a generalização dos resultados aqui apresentados. Porém, no caso do presente estudo, é possível generalizar os resultados uma vez que a VDFM é 
uma problemática estrutural e que atinge a sociedade como um todo, independente de classe social, localidade ou qualquer outro recorte. O Estado reforça posturas machistas e que precisam ser combatidas (Dias, 2015).

Considerando que a problemática é um fenômeno dinâmico e latente na sociedade em geral, reitera-se a importância do levantamento de dados mais detalhados - mais recortes temporais, localidades com mais ou menos recorrência de VDFM, entre outros para subsidiar estudos e políticas públicas. Salientamos também a necessidade de realizar estudos que observem a perspectiva da vítima, fundamental para a otimização da rede de apoio e enfrentamento à VDFM.

\section{REFERÊNCIAS BIBLIOGRÁFICAS}

ABNT NBR ISO 31000, de 28 de março de 2018. Gestão de Riscos - Diretrizes. São Paulo: Associação Brasileira de Normas Técnicas.

Abuhammad, S. (2020). Violence Against Jordanian Women During COVID $\square 19$ Outbreak. International Journal of Clinical Practice, 75(3), 1-7. Recuperado de https://doi. org/10.1111/ijcp.13824

Aguiar, J. M., D’Oliveira, A. F. P. L., \& Schraiber, L. B. (2020). Mudanças históricas na rede intersetorial de serviços voltados à violência contra a mulher - São Paulo, Brasil. Interface - Comunicação, Saúde, Educação, 24, 1-16. Recuperado de https://doi. org/10.1590/interface.190486

Angelim, F. P. (2009). A Importância da Intervenção Multidisciplinar Face à Complexidade da Violência Doméstica. In Lima, F. R, \& Santos, C. Violência doméstica: vulnerabilidades e desafios na intervenção criminal e multidisciplinar (pp. 125-136). Rio de Janeiro: Lumen Juris.

Ávila, T. P. (2017). Políticas Públicas de Prevenção Primária à Violência Contra a Mulher: Lições da Experiência Australiana. Revista Gênero, 17(2), 95-125. Recuperado de https://doi.org/10.22409/rg.v17i2.944

Ávila, T. P. (2018). Articulação do trabalho em rede para a proteção à mulher em situação de violência doméstica e familiar. In Brasil, CNMP. Violência contra a mulher: um olhar do Ministério Público Brasileiro (pp. 141-163). Brasília: CNMP.

Ávila, T. A. P., Machado, B. A., Suxberger, A. H. G., \& Távora, M. F. (2014). Modelos europeus de enfrentamento à violência de gênero: experiências e representações sociais. Brasília: ESMPU.

Bandeira, L. M., \& Almeida, T. M. C. (2014). A “Eficácia” da Lei Maria da Penha sob diferentes perspectivas. In Stevens, C., Oliveira, S. R., \& Zanello, V. Estudos Feministas e de Gênero: Articulações e Perspectivas (pp. 476-489). Ilha de Santa Catarina: Editora Mulheres. 
Bardin, L. (2016). Análise de Conteúdo. São Paulo: Edições 70.

Bassan, P. (2020, março 23). Casos de violência doméstica no RJ crescem $50 \%$ durante confinamento. Portal G1, RJ2. Recuperado de https://g1.globo.com/ri/rio-de-janeiro/ noticia/2020/03/23/casos-de-violencia-domestica-no-rj-crescem-50percent-duranteconfinamento.ghtml

Blay,E.A.(2003). Violênciacontraamulhere políticas públicas. EstudosAvançados, 17(49), 8798. Recuperado de https://www.scielo.br/j/ea/a/ryqNRHj843kKKHjLkgrms9k/?lang=pt

Bradbury $\square$ Jones, C., \& Isham, L. (2020). The pandemic paradox: The consequences of COVID $\square 19$ on domestic violence. Journal of Clinical Nursing, 29(13-14), 2047-2049. Recuperado de https://doi.org/10.1111/jocn.15296

Brasil. Constituição da República Federativa do Brasil de 1988. Recuperado de http://www. planalto.gov.br/ccivil 03/constituicao/constituicaocompilado.htm

Brasil. Lei $N^{0}$ 11.340, de 7 de agosto de 2006. Recuperado de http://www.planalto.gov.br/ ccivil 03/ ato2004-2006/2006/lei/l11340.htm

Brasil. Lei $N^{0}$ 14.149, de 5 de maio de 2021. Recuperado de http://www.planalto.gov.br/ ccivil 03/ Ato2019-2022/2021/Lei/L14149.htm

Brasil. Resolução Conjunta CNJ/CNMP N 5, de 3 de março de 2020. Recuperado de https:// www.cnmp.mp.br/portal/atos-e-normas/norma/7197/

Bueno, S., \& Lima, R. S. (Coords.). (2019). Visível e Invisível: A Vitimização de Mulheres no Brasil (2a Edição). São Paulo: Fórum Brasileiro de Segurança Pública. Recuperado de https://www.forumseguranca.org.br/wp-content/uploads/2019/02/relatorio-pesquisa2019-v6.pdf

Campos, B., Tchalekian, B., \& Paiva, V. (2020). Violência Contra a Mulher: Vulnerabilidade Programática em Tempos de SARS-COV-2/ COVID-19 em São Paulo. Psicologia \& Sociedade, 32,1-20. Recuperado de https://doi.org/10.1590/1807-0310/2020v32240336

Canal, G. C., Alcantara, N. S. A., \& Machado, I. V. (2019). Feminicídio: o gênero de quem mata e de quem morre. Serviço Social em Revista, 21(2), 333. Recuperado de https:// doi.org/10.5433/1679-4842.2019v21n2p333

Carneiro, J. B., Gomes, N. P., Estrela, F. M., Santana, J. D., Mota, R. S., \& Erdmann, A. L. (2017). Domestic violence: repercussions for women and children. Escola Anna Nery, 21(4), 1-7. Recuperado de https://doi.org/10.1590/2177-9465-ean-2016-0346

CEARÁ. (2020). ESTATíSTICAS - Secretaria da Segurança Pública e Defesa Social. Recuperado de https://www.sspds.ce.gov.br/estatisticas-2/

Cerqueira, D., Matos, M., Martins, A. P. A., \& Junior, J. P. (2015). Avaliando a efetividade da Lei Maria da Penha. Brasília: IPEA. Recuperado de http://repositorio.ipea.gov.br/ bitstream/11058/3538/1/td_2048.pdf 
Dias, M. B. (2015). Lei Maria da Penha: A efetividade da Lei 11.340/2006 de combate à violência doméstica e familiar contra a mulher (4⿳亠丷⿵冂丶 edição). São Paulo: Revista dos Tribunais.

Ellsberg, M., Arango, D. J., Morton, M., Gennari, F., Kiplesund, S., Contreras, M., \& Watts, C. (2015). Prevention of violence against women and girls: what does the evidence say? The Lancet, 385(9977), 1555-1566. Recuperado de https://doi.org/10.1016/S0140$\underline{6736(14) 61703-7}$

Graham-Harrison, E., Giuffrida, A., Smith, H., \& Ford, L. (2020, março 28). Lockdowns around the world bring rise in domestic violence. The Guardian, Domestic violence. Recuperado de https://www.theguardian.com/society/2020/mar/28/lockdowns-worldrise-domestic-violence

Espinosa-Bejarano, M. P. (2020). Enemigo silente durante la pandemia COVID-19 en Colombia: "La violencia contra la mujer". Salutem Scientia Spiritus, 6(1), 181-186. Recuperado de https://revistas.javerianacali.edu.co/index.php/salutemscientiaspiritus/ article/view/2368/2885

FBSP. (2020). Violência doméstica durante a pandemia de COVID-19 Edição 03. Recuperado de https://forumseguranca.org.br/publicacoes posts/violencia-domestica-durantepandemia-de-covid-19-edicao-03/

FBSP. (2021). Anuário Brasileiro de Segurança Pública. Recuperado de https:// forumseguranca.org.br/wp-content/uploads/2021/07/anuario-2021-completo-v6-bx.pdf

Fernandes, V. D. S. (2015). Lei Maria da Penha: o processo penal no caminho da efetividade: abordagem jurídica e multidisciplinar (inclui Lei de feminicídio). São Paulo: Atlas.

Ferreira, M. D. (2020). A violência doméstica contra a mulher e a ineficácia das medidas protetivas previstas na Lei 11.340/06 (Trabalho de Conclusão de Curso). Universidade Católica de Goiás (PUCGOIÁS), Goiânia, GO, Brasil. Recuperado de https://repositorio. pucgoias.edu.br/jspui/handle/123456789/935

FRA. (2014). Violence against women: an EU-wide survey Main results report. Luxembourg: Publications Office of the European Union. Recuperado de https://fra.europa.eu/en/ publication/2014/violence-against-women-eu-wide-survey-main-results-report

Gil, A. C. (2021). Como elaborar projetos de pesquisa (6 $6^{\mathrm{a}}$ ed.). São Paulo: Atlas.

Gulati, G., \& Kelly, B. D. (2020). Domestic violence against women and the COVID-19 pandemic: What is the role of psychiatry? International Journal of Law and Psychiatry, 71(June), 101594. Recuperado de https://doi.org/10.1016/j.ijlp.2020.101594

Heise, L. L. (2011). What works to prevent partner violence: An evidence Overview. Recuperado de https://www.researchgate.net/publication/292047239 What Works to Prevent Partner Violence An Evidence Overview 
Jorge, M., Ribeiro, L. C. S., Santana, J. R., Andrade, J. R. L. (2020), Moura, F, Esperidião, F., Santos, F. R., \& Simões, H. P. Estimação de impactos sobre a criminalidade da pandemia COVID-19 em Sergipe - Parte IV: março a julho de 2020. Boletim Informativo Mensal LEADER-UFS $n^{\circ}$ 10-2020. Recuperado de https://www.researchgate.net/ publication/347409535 Estimacao de impactos sobre a criminalidade da pandemia COVID-19 em Sergipe - Parte IV marco a julho de 2020 - Aracaju

Krug, E. G., Dahlberg, L. L., Mercy, J. A., Zwi, A. B., \& Lozano, R. (2002). World report on violence and health. World Health Organization. Recuperado de http://apps.who.int/iris/ bitstream/handle/10665/42495/9241545615 eng.pdf?sequence $=1$

Lisboa, T. K. (2014). Violência de gênero, políticas públicas para o seu enfrentamento e o papel do serviço social. Temporalis, 14(27), 33-56. Recuperado de https://doi. org/10.22422/2238-1856.2014v14n27p33-56

Lobo, J. C. (2020). Uma outra pandemia no Brasil: as vítimas da violência doméstica no isolamento social e a "incomunicabilidade da dor". Tessituras: Revista de Antropologia e Arqueologia, 8(1), 20-26. Recuperado de https://doi.org/https://doi.org/10.15210/tes. v8i0.18901

Marcolino, E. C., Santos, R. C., Clementino, F. S., Leal, C. Q. A. M., Soares, M. C. S., Miranda, F. A. N., \& Souto, R. Q. (2021). O distanciamento social em tempos de Covid-19: uma análise de seus rebatimentos em torno da violência doméstica. Interface - Comunicação, Saúde, Educação, 25(supl. 1), 1-19. https://doi.org/10.1590/interface.200363

Marques, E. S., Moraes, C. L., Hasselmann, M. H., Deslandes, S. F., \& Reichenheim, M. E. (2020). A violência contra mulheres, crianças e adolescentes em tempos de pandemia pela COVID-19: panorama, motivações e formas de enfrentamento. Cadernos de Saúde Pública, 36(4). https://doi.org/10.1590/0102-311x00074420

Matosinhos, I. D. (2018). O Ministério Público como agente transformador da realidade social no combate da violência doméstica e promoção da igualdade de gênero. In Brasil, CNMP. Violência contra a mulher: um olhar do Ministério Público Brasileiro (pp. 63-82). Brasília: CNMP.

Melo, B. D., Lima, C. C., Moraes, C. L., Andrade, C. B., Pereira, D. R., Souza, E. R., Ribeiro, F. M. L., Serpeloni, F., Avanci, J. Q., Kabad, J. F., Njaine, K., Deslandes, S. F., Schenker, M., Souza, M. S., Magrin, N. P., Assis, S. G., Zanello, V., Silva, V. L. M., Kadri, M., \& Rabelo, I. V. M. (Orgs.) (2020). Saúde mental e atenção psicossocial na pandemia COVID-19: violência doméstica e familiar na COVID-19. Rio de Janeiro: Fiocruz. Recuperado de https://www.arca.fiocruz.br/handle/icict/41121

Michau, L., Horn, J., Bank, A., Dutt, M., \& Zimmerman, C. (2015). Prevention of violence against women and girls: lessons from practice. The Lancet, 385(9978), 1672-1684. Recuperado de https://doi.org/10.1016/S0140-6736(14)61797-9 
MMFDH. (2020, março 27). Coronavírus: sobe o número de ligações para canal de denúncia de violência doméstica na quarentena. Recuperado de https://www.gov.br/mdh/pt-br/ assuntos/noticias/2020-2/marco/coronavirus-sobe-o-numero-de-ligacoes-para-canalde-denuncia-de-violencia-domestica-na-quarentena

Monteiro, S. A. S., Yoshimoto, E., \& Ribeiro, P. R. M. (2020). A produção acadêmica sobre a questão da violência contra a mulher na emergência da pandemia da COVID-19 em decorrência do isolamento social. Doxa: Revista Brasileira de Psicologia e Educação, 22(1), 152-170. Recuperado de https://doi.org/10.30715/doxa.v22i1.13976

Nittari, G., Sagaro, G. G., Feola, A., Scipioni, M., Ricci, G., \& Sirignano, A. (2021). First Surveillance of Violence against Women during COVID-19 Lockdown: Experience from "Niguarda" Hospital in Milan, Italy. International Journal of Environmental Research and Public Health, 18(7), 3801. Recuperado de https://doi.org/10.3390/ijerph18073801

Noman, A. H. M., Griffiths, M. D., Pervin, S., \& Ismail, M. N. (2021). The detrimental effects of the COVID-19 pandemic on domestic violence against women. Journal of Psychiatric Research, 134(June 2020), 111-112. Recuperado de https://doi.org/10.1016/j. ipsychires.2020.12.057

Okabayashi, N. Y. T., Tassara, I. G., Casaca, M. C. G., Falcão, A. A., \& Bellini, M. Z. (2020). Violência contra a mulher e feminicídio no Brasil - impacto do isolamento social pela COVID-19. Brazilian Journal of Health Review, 3(3), 4511-4531. Recuperado de https:// doi.org/10.34119/bjhrv3n3-049

Oliveira, M., Machado, F., \& Lima, M. S. (2020). Violência contra a mulher em tempos de pandemia : ações educativas de combate e prevenção e suas fragilidades em Manaus/ AM. Conedu-VII Congresso Nacional de Educação, 13. Recuperado de https:// editorarealize.com.br/editora/anais/conedu/2020/TRABALHO EV140 MD1 SA7 ID7718 01102020114305.pdf

ONU. (1993). General Assembly Resolution $n^{\circ}$ 48/104. Declaration on the Elimination of Violence Against Women (20 December, 1993). Recuperado de https://digitallibrary. un.org/record/179739

ONU. (2016). ONU: Taxa de feminicídios no Brasil é quinta maior do mundo; diretrizes nacionais buscam solução. Recuperado de https://brasil.un.org/pt-br/72703-onu-taxade-feminicidios-no-brasil-e-quinta-maior-do-mundo-diretrizes-nacionais-buscam

ONU. (2020). Relatora da ONU recebe informações sobre violência contra mulheres durante crise de COVID-19 | As Nações Unidas no Brasil. Recuperado de https://brasil.un.org/ pt-br/85571-relatora-da-onu-recebe-informacoes-sobre-violencia-contra-mulheresdurante-crise-de-covid-19

Our Watch. (2021). Change the story | Preventing violence against women. Recuperado de https://www.ourwatch.org.au/change-the-story/ 
Paraná. (2018). Entenda a Lei Maria da Penha. Recuperado de https://www.justiça.pr.gov. br/sites/default/arquivos restritos/files/migrados/File/divulgação/Guia-Lei-Maria-daPenha.pdf

Pasinato, W. (2016). Diretrizes nacionais do Feminicídio - Investigar, processar e julgar com a perspectiva de gênero. As mortes violentas de mulheres. Recuperado de https://www. onumulheres.org.br/wp-content/uploads/2016/04/diretrizes feminicidio FINAL.pdf

Pasinato, W., Machado, B. A., \& Ávila, T. P. (2019). Políticas públicas de prevenção à violência contra a mulher. São Paulo: Marcial Pons.

Peres, A. C. (2020, maio 21). "Socorro! Socorro!". Fiocruz, RADIS. Recuperado de https:// radis.ensp.fiocruz.br/index.php/home/entrevista/socorro-socorro

Peterman, A., Potts, A., O'Donnell, M., Thompson, K., Shah, N., Oertelt-Prigione, S., \& Gelder, N. V. (2020). Pandemics and Violence Against Women and Children. Center for Global Development, Working Paper 528. Recuperado de https://www.cgdev.org/ publication/pandemics-and-violence-against-women-and-children

Prestes, L. A. (2021). A utilização do Formulário Nacional de Avaliação de Risco para a decretação da prisão preventiva do agressor no contexto de violência doméstica e familiar contra a mulher. (Trabalho de Conclusão de Curso). Universidade Federal do Paraná, Curitiba, PR, Brasil. Recuperado de https://acervodigital.ufpr.br/handle/1884/71221

190 RIO GRANDE DO SUL. (2020). Indicadores da Violência Contra a Mulher - Lei Maria da Penha - Secretaria da Segurança Pública. Recuperado de https://ssp.rs.gov.br/ indicadores-da-violencia-contra-a-mulher

Saffioti, H. (2015). Genêro, Patriarcado e Violência (2a ed). São Paulo: Expressão Popular.

Sampieri, R. H., Collado, C. F., \& Lucio, M. D. P. B. (2006). Metodologia de Pesquisa (3a Ed.). São Paulo: McGraw-Hill.

Santos, J. S., Santos, T., Souza, C. R. V., \& Souza, F. O. (2020). Relações abusivas: um estudo contemporâneo sobre a violência doméstica em Nossa Senhora das Dores/ Sergipe. Caderno de Graduação - Ciências Humanas e Sociais - UNIT - SERGIPE, 6(2), 277-294. Recuperado de https://periodicos.set.edu.br/cadernohumanas/article/ view/8829

Secchi, L. (2017). Análise de políticas públicas: diagnóstico de problemas, recomendação de soluções. São Paulo: Cengage Learning.

Sommariva, S. S., \& Hugill, M. S. G. (Orgs.) (2020). Gênero bate à porta do judiciário: Aplicando o Formulário Nacional de Avaliação de Risco. Santa Catarina: TJ-SC / CEJUR / Academia Judicial. Recuperado de https://www.tjsc.jus.br/web/academia-judicial/-/ genero-bate-a-porta-do-judiciario-e-novo-titulo-na-secao-de-e-books-da-aj 
Suga, T. (2021). Protecting women: new domestic violence countermeasures for COVID-19 in Japan. Sexual and Reproductive Health Matters, 29(1), 1874601. Recuperado de https://doi.org/10.1080/26410397.2021.1874601

Tavares, M., \& Medeiros, M. N. (2015). Avaliação de risco em casos de violência contra a mulher perpetrada por parceiro íntimo. (Tese de Doutorado). Universidade de Brasília, Brasília, DF, Brasil. Recuperado de https://repositorio.unb.br/handle/10482/20191

TOCANTINS. (2020). Balanço da Segurança Pública. Recuperado de https://www.to.gov.br/ ssp/balanco-da-seguranca-publica/6cio1602f3pg

Valera, E. M. (2020). When pandemics clash: Gendered violence-related traumatic brain injuries in women since COVID-19. EClinicalMedicine, 24, 100423. Recuperado de https://doi.org/10.1016/j.eclinm.2020.100423

Vieira, P. R., Garcia, L. P., \& Maciel, E. L. N. (2020). Isolamento social e o aumento da violência doméstica: o que isso nos revela? Revista Brasileira de Epidemiologia, 23, 1-5. Recuperado de https://doi.org/10.1590/1980-549720200033

Waiselfisz, J. J. (2015). Mapa da Violência 2015: Homicídio de mulheres no Brasil (Vol. 1). Brasília: Flacso Brasil. Recuperado de https://www.onumulheres.org.br/wp-content/ uploads/2016/04/MapaViolencia_2015 mulheres.pdf

Walker, L. E. (1979). The Battered Woman. New York: Harper \& Row.

Yin, R. K. (2015). Estudo de caso: planejamento e métodos (5 $5^{\mathrm{a}}$ Ed.). Porto Alegre: Bookman.

\section{Dados dos autores:}

\section{Thaís Santos Doria}

(iD) ORCID: https://orcid.org/0000-0003-2376-6116

Mestranda em Administração Pública (PROFIAP) pela Universidade Federal de Sergipe. Assistente em Administração na Universidade Federal de Sergipe. São Cristóvão, Sergipe, Brasil. E-mail: thaisdoria@academico.ufs.br.

\section{Gustavo Torres de Brito Daier}

(iD) ORCID: https://orcid.org/0000-0002-9535-0331

Mestrando em Administração Pública (PROFIAP) pela Universidade Federal de Sergipe. Assistente em Administração na Universidade Federal de Sergipe. São Cristóvão, Sergipe, Brasil. E-mail: gdaier@academico.ufs.br.

\section{Kleverton Melo De Carvalho}

(iD) ORCID: https://orcid.org/0000-0003-1969-7955

Doutor em Administração. Professor do Programa de Pós-Graduação Profissional em Administração Pública (PROFIAP) da Universidade Federal de Sergipe (UFS). São Cristóvão Sergipe, Brasil. E-mail: kleverton1@academico.ufs.br. 


\section{Rosângela Sarmento Silva}

(D) ORCID: https://orcid.org/0000-0002-3044-9699

Doutora em Administração. Professora do Programa de Pós-Graduação em Administração (PROPADM) e do Programa de Pós-Graduação Profissional em Administração Pública - (PROFIAP) da Universidade Federal de Sergipe (UFS). São Cristóvão Sergipe, Brasil. E-mail: rosangelasarmento13@gmail.com.

Como citar este artigo:

Doria, T. S., Daier, G. T. B., Carvalho, K. M., \& Silva, R. S. (2021). Dimensões dos Riscos nas Políticas de Combate à Violência Contra a Mulher Durante a Pandemia de Covid-19 em Aracaju (Sergipe). AOS - Amazônia, Organizações e Sustentabilidade, 10(2). http://dx.doi.org/10.17648/aos.v10i2.2472 